\title{
The Stagnation Regime of the New Keynesian Model and Recent US Policy*
}

\author{
George W. Evans \\ University of Oregon \\ University of St. Andrews
}

October 30, 2010. Revised: April 2, 2011.

\begin{abstract}
In Evans, Guse, and Honkapohja (2008) the intended steady state is locally but not globally stable under adaptive learning, and unstable deflationary paths can arise after large pessimistic shocks to expectations. In the current paper a modified model is presented that includes a locally stable stagnation regime as a possible outcome arising from large expectation shocks. Policy implications are examined. Sufficiently large temporary increases in government spending can dislodge the economy from the stagnation regime and restore the natural stabilizing dynamics. More specific policy proposals are presented and discussed.
\end{abstract}

JEL Classification: E63, E52, E58.

Keywords: Stagnation, fiscal and monetary policy, deflation trap

*Previously titled "The Stagnation Regime of the New Keynesian Model and Current US Policy." I am indebted to the University of Oregon Macro workshop for comments on the first draft of this paper, to Mark Thoma for several further discussions and to James Bullard, Seppo Honkpohja, Frank Smets, Jacek Suda and George Waters for comments. Of course, the views expressed in this paper remain my own. Financial support from National Science Foundation Grant no. SES-1025011 is gratefully acknowledged. 
This paper, which was written in October 2010, has two parts: (i) a theoretical part that develops a model in which there are paths that converge to a "stagnation regime" with deflation and a continuum of low output steady states; and (ii) a policy-oriented part, motivated by both the model and recent US experience, that discusses practical monetary and fiscal policy issues when stagnation is a concern. Significant changes to US macro policy were made in November and December 2010. These policy changes, as well as the trajectory of key US macro data over November 2010 - March 2011, are summarized in the Postscript and noted briefly in the main text.

\section{Introduction}

The economic experiences of 2008-10 have highlighted the issue of appropriate macroeconomic policy in deep recessions. A particular concern is what macroeconomic policies should be used when slow growth and high unemployment persist even after the monetary policy interest rate instrument has been at or close to the zero net interest rate lower bound for a sustained period of time. In Evans, Guse, and Honkapohja (2008) and Evans and Honkapohja (2010), using a New Keynesian model with learning, we argued that if the economy is subject to a large negative expectational shock, such as plausibly arose in response to the financial crisis of 2008-9, then it may be necessary, in order to return the economy to the targeted steady state, to supplement monetary policy with fiscal policy, in particular with temporary increases in government spending.

The importance of expectations in generating a "liquidity trap" at the zero-lower bound is now widely understood. For example, Benhabib, SchmittGrohe, and Uribe (2001b), Benhabib, Schmitt-Grohe, and Uribe (2001a) show the possibility of multiple equilibria under perfect foresight, with a continuum of paths to an unintended low or negative inflation steady state. ${ }^{1}$ Recently, Bullard (2010) has argued that data from Japan and the US over 2002-2010 suggest that we should take seriously the possibility that "the US economy may become enmeshed in a Japanese-style deflationary outcome within the next several years."

The learning approach provides a perspective on this issue that is quite

\footnotetext{
${ }^{1}$ See Krugman (1998) for a seminal discussion and Eggertsson and Woodford (2003) for a recent analyses and references.
} 
different from the rational expectations results. ${ }^{2}$ As shown in Evans, Guse, and Honkapohja (2008) and Evans and Honkapohja (2010), when expectations are formed using adaptive learning, the targeted steady state is locally stable under standard policy, but it is not globally stable. However, the potential problem is not convergence to the deflation steady state, but instead unstable trajectories. The danger is that sufficiently pessimistic expectations of future inflation, output and consumption can become self-reinforcing, leading to a deflationary process accompanied by declining inflation and output. These unstable paths arise when expectations are pessimistic enough to fall into what we call the "deflation trap." Thus, while in Bullard (2010) the local stability results of the learning approach to expectations is characterized as one of the forms of denial of "the peril," the learning perspective is actually more alarmist in that it takes seriously these divergent paths.

As we showed in Evans, Guse, and Honkapohja (2008), in this deflation trap region aggressive monetary policy, i.e. immediate reductions on interest rates to close to zero, will in some cases avoid the deflationary spiral and return the economy to the intended steady state. However, if the pessimistic expectation shock is too large then temporary increases in government spending may be needed. The policy response in the US, UK and Europe has to some extent followed the policies advocated in Evans, Guse, and Honkapohja (2008). Monetary policy was quick, decisive and aggressive, with, for example, the US federal funds rate reduced to near zero levels by the end of 2008. In the US, in addition to a variety of less conventional interventions in the financial markets by the Treasury and the Federal Reserve, including the TARP measures in late 2008 and a large scale expansion of the Fed balance sheet designed to stabilize the banking system, there was the $\$ 727$ billion ARRA stimulus package passed in February 2009.

While the US economy then stabilized, the recovery through 2010 was weak and the unemployment rate remained both very high and roughly constant for the year through November 2010. At the same time, although inflation was low, and hovering on the brink of deflation, we did not see the economy recording large and increasing deflation rates. ${ }^{3}$ From the viewpoint of Evans, Guse, and Honkapohja (2008), various interpretations of the data are possible, depending on one's view of the severity of the initial negative

\footnotetext{
${ }^{2}$ For a closely related argument see Reifschneider and Williams (2000).

${ }^{3}$ However the CPI 12-month inflation measure, excluding food and energy, did show a downward trend over 2007 - 2010, and in December 2010 was at $0.6 \%$.
} 
expectations shock and the strength of the monetary and fiscal policy impacts. However, since recent US (and Japanese) data may also be consistent with convergence to a deflation steady state, it is worth revisiting the issue of whether this outcome can in some circumstances arise under learning.

In this paper I develop a modification of the model of Evans, Guse, and Honkapohja (2008) that generates a new outcome under adaptive learning. Introducing asymmetric adjustment costs into the Rotemberg model of price setting leads to the possibility of convergence to a stagnation regime following a large pessimistic shock. In the stagnation regime, inflation is trapped at a low steady deflation level, consistent with zero net interest rates, and there is a continuum of consumption and output levels that may emerge. Thus, once again, the learning approach raises the alarm concerning the evolution of the economy when faced with a large shock, since the outcome may be persistently inefficiently low levels of output. This is in contrast to the rational expectations approach of Benhabib, Schmitt-Grohe, and Uribe (2001b), in which the deflation steady state has output levels that are not greatly different from the targeted steady state.

In the stagnation regime, fiscal policy, taking the form of temporary increases in government spending, is important as a policy tool. Increased government spending raises output, but leaves the economy within the stagnation regime until raised to the point at which a critical level of output is reached. Once output exceeds the critical level, the usual stabilizing mechanisms of the economy resume, pushing consumption, output and inflation back to the targeted steady state, and permitting a scaling back of government expenditure.

After introducing the model, and exploring its principal policy implications, I discuss the policy options more generally for the US economy.

\section{The Model}

We use the model of Evans, Guse, and Honkapohja (2008), itself a discretetime version of Benhabib, Schmitt-Grohe, and Uribe (2001b), but with rational expectations replaced by adaptive learning. The model is a stylized "New Keynesian" model of the type that underlies widely-used DSGE models. For simplicity we use the version without capital and with consolidated household-firms. As in Benhabib, Schmitt-Grohe, and Uribe (2001b), the pricing friction is modeled as a cost of adjusting prices, in the spirit of Rotem- 
berg (1982), rather than a Calvo-type friction. An important advantage of the Rotemberg pricing friction is that the resulting model does not need to be linearized, making global analysis possible.

Details of the model are given in the Appendix. For simplicity I use a nonstochastic version of the model. The dynamic first-order Euler conditions, satisfied by optimal decision-making, lead to aggregate equations of the form

$$
\begin{aligned}
\pi_{t} & =H_{\pi}\left(\pi_{t+1}^{e}, c_{t}, g_{t}\right) \\
c_{t} & =H_{c}\left(\pi_{t+1}^{e}, c_{t+1}^{e}, R_{t}\right),
\end{aligned}
$$

where $c_{t}$ is consumption at time $t, \pi_{t}$ is the inflation factor, $g_{t}$ is government purchases of goods and services and $R_{t} \geq 1$ is the interest-rate factor on one-period debt. Equation (1) is the "Phillips equation" for this model, and equation (2) is the "IS equation." The functions $H_{\pi}$ and $H_{c}$ are determined by equations (7)-(8) in the Appendix. When linearized at a steady state both equations take the standard form. Because this is a model without capital, aggregate output satisfies $y_{t}=c_{t}+g_{t}$.

Under the learning approach followed here, we treat equations (1)-(2) as arising from aggregations of the corresponding behavioral equations of individual agents, and assume that they hold whether or not the expectations held by agents are fully "rational." Put differently, (1)-(2) are temporary equilibrium equations that determine $\pi_{t}$ and $c_{t}$, given government purchases $g_{t}$, the interest rate $R_{t}$ and expectation $c_{t+1}^{e}$ and $\pi_{t+1}^{e} \cdot{ }^{4}$

The particular from of the Phillips equation arises from a quadratic inflation adjustment $\operatorname{cost} k\left(\pi_{t, j}\right)=0.5\left(\pi_{t, j}-1\right)^{2}$, where $\pi_{t, j}=\frac{P_{t, j}}{P_{t-1, j}}$ is the inflation factor for agent $j$ 's good. The IS equation (2) is simply the standard consumption Euler equation obtained from $u^{\prime}\left(c_{t, j}\right)=\beta\left(R_{t} / \pi_{t+1}^{e}\right) u^{\prime}\left(c_{t+1, j}^{e}\right)$, where $u(c)$ is the utility of consumption and $0<\beta<1$ is the discount factor. Note that because $\pi_{t}$ measures the gross inflation rate (or inflation factor), $\pi_{t}-1$ is the usual net inflation rate. Similarly $\beta^{-1}-1$ is the net discount rate, $R_{t}-1$ is the net interest rate and $R_{t}=1$ corresponds to the zero lower bound on interest rates. The variables $c_{t+1}^{e}$ and $\pi_{t+1}^{e}$ denote the time $t$ expectations of the values of these variables in $t+1$.

\footnotetext{
${ }^{4}$ In the learning literature the formulation (1)-(2) is sometimes called the Euler-learning approach. This approach emphasizes short planning horizons, in contrast to the infinitehorizon approach emphasized, for example, in Preston (2006). In Evans and Honkapohja (2010) we found that the main qualitative results obtained in Evans, Guse, and Honkapohja (2008) carried over to an infinite-horizon learning formulation.
} 
We next discuss fiscal and monetary policy. We assume that in normal times government spending is constant over time, i.e. $g_{t}=g>0$. The government's flow budget constraint is that government spending plus interest must be financed by taxes, debt and seigniorage. Taxes are treated as lumpsum and are assumed to follow a feedback rule with respect to government debt, with a feedback parameter that ensures convergence to a specified finite debt level in a steady state equilibrium.

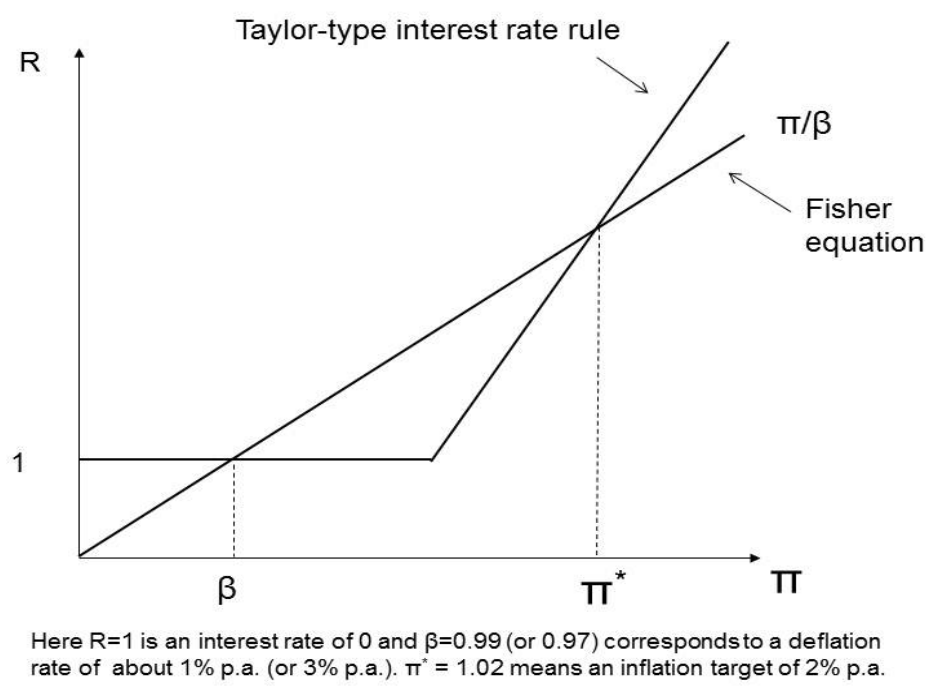

Figure 1: The Taylor rule and Fisher equation.

Monetary policy is assumed to follow a continuous nondecreasing interestrate rule ${ }^{5}$

$$
R_{t}=f\left(\pi_{t+1}^{e}\right) .
$$

We assume the monetary authorities have an inflation target $\pi^{*}>1$. For example if the inflation target is $2 \%$ p.a. then $\pi^{*}=1.02$. From the consumption Euler equation it can be seen that at a steady state $c_{t}=c_{t+1}^{e}=c$, $\pi_{t}=\pi_{t+1}^{e}=\pi$, and $R_{t}=R$, the Fisher equation

$$
R=\pi / \beta
$$

\footnotetext{
${ }^{5}$ Here for convenience we assume $R_{t}$ is set on the basis of $\pi_{t+1}^{e}$ instead of $\pi_{t}$ as in Evans, Guse, and Honkapohja (2008).
} 
must be satisfied, and the steady state real interest rate factor is $\beta^{-1}$. The function $f(\pi)$ is assumed to be consistent at $\pi^{*}$ with the Fisher equation, i.e. $f\left(\pi^{*}\right)=\pi^{*} / \beta$. In addition we assume that $f^{\prime}\left(\pi^{*}\right)>\beta^{-1}$, so that the Taylor principle is satisfied at $\pi^{*}$. Because of the ZLB (zero lower bound on net interest rates) there will also be another steady state at a lower inflation rate, and if (3) is such that $R_{t}=1$ at low $\pi_{t+1}^{e}$ then the other steady state is one of deflation, corresponding to inflation factor $\pi=\beta<1$. For simplicity I will assume a linear spline rule of the form shown in Figure 1. Figure 1, which graphs this interest rate rule combined with the steady state Fisher equation, shows that there are two steady states that arise in this model, the targeted steady state at $\pi^{*}$ and the unintended steady state at $\pi=\beta$, which corresponds to a deflation rate at the net discount rate.

Finally we need to specify how expectations are updated over time. Since we have omitted all exogenous random shocks in the model we can choose a particularly simple form of adaptive learning rule, namely

$$
\begin{aligned}
\pi_{t+1}^{e} & =\pi_{t}^{e}+\phi\left(\pi_{t-1}-\pi_{t}^{e}\right) \\
c_{t+1}^{e} & =c_{t}^{e}+\phi\left(c_{t-1}-c_{t}^{e}\right),
\end{aligned}
$$

where $0<\phi<1$ parameterizes the response of expectations to the most recent data point and is usually assumed to be small. If there were observable random shocks in the model, then a more general formulation would be a form of least-squares learning in which the variables to be forecasted are regressed on the exogenous observables and an intercept. ${ }^{6}$ This would not alter the qualitative results. The crucial assumption of adaptive learning is that expectations are driven by the evolution of observed data. This might be thought of as the "Missouri" view of expectations, since Missouri's official motto is the "Show Me state". On the adaptive learning approach, agents are unlikely to increase or decrease their forecasts, say, of inflation unless they have data-based reasons for doing so. ${ }^{7}$

This completes the description of the model. In summary the dynamics of the model is determined by (i) a temporary equilibrium map (1)-(2), the

\footnotetext{
${ }^{6}$ If habit persistence, indexation, lags and/or serially correlated exogenous shocks were present, then least-squares-type learning using vector autoregessions would be appropriate.

${ }^{7}$ The adaptive learning approach can be extended to incorporate credible expected future interest rate policy, as announced by the Fed. See Evans, Honkapohja, and Mitra (2009) for a general discussion of incorporating forward-looking structural information into adaptive learning frameworks. In Evans and Honkapohja (2010) we assume that private agents know the policy rule used by the central bank in setting interest rates.
} 
interest-rate rule (3), government spending $g_{t}=g$ and (ii) the expectations updating rules (4)-(5). As is well-known (e.g. see Evans and Honkapohja (2001)) for small $\phi$ the dynamics are well approximated by a corresponding ordinary differential equation and hence, for the case at hand, by a twodimensional phase diagram. This is illustrated by Figure A1 in the Appendix. Corresponding phase diagrams were given in Evans, Guse, and Honkapohja (2008) for an interest-rate rule $R_{t}=f\left(\pi_{t}\right)$ with $f$ a smooth, increasing, convex function. Qualitatively the results show the results described in the Introduction: the $\pi^{*}$ steady state is locally stable, while the deflation steady state is locally unstable, taking the form of a saddle, with a deflation trap region in the southwest part of the space. In the deflation trap region trajectories are unstable and follow divergent trajectories under learning.

The model, of course, is very simple and highly stylized. More realistic versions would incorporate various elements standard in DSGE models, such as habit persistence, partial indexation, separate wage and price dynamics, capital and costs of adjusting the capital stock, and explicit models of job search and unemployment, as well as a model of financial intermediation. Thus the model here is very simple and incomplete. Nonetheless it provides a story of some key mechanisms that are of great concern to policymakers.

\section{A Modified Model}

We now come to the modification mentioned in the Introduction. To motivate this we briefly reflect on the experience of the US in the 1930s, the Japanese economy since the mid 1990s, and the experience of the US over 2007-2010, as well as the data summary in Figure 1 of Bullard (2010). According to Evans, Guse, and Honkapohja (2008), if we are in the unstable region then we will eventually see a deflationary spiral, with eventually falling deflation rates. However we have not seen this yet in the US, and this has not happened in Japan, despite an expended period of deflation. Similarly, in the US in the 1930s, after two or three years of marked deflation, the inflation rate stabilized at near zero rates. $^{8}$ At the same time, output was greatly depressed, and unemployment much higher, in the US in the 1930s, and low output growth and elevated unemployment rates have also been seen

\footnotetext{
${ }^{8}$ The initial significant deflation in 1931 and 1932 can perhaps be explained as due to reverse bottleneck effects (as in Evans (1985)), i.e. reductions in prices when demand falls for goods that had been at capacity production in the prior years.
} 
since the mid 1990s in Japan.

There are a number of avenues within the model that could explain these outcomes. As noted by Evans, Guse, and Honkapohja (2008), if policymakers do use aggressive fiscal policy to prevent inflation falling below a threshold, but choose that threshold too low, then this can lead to another locally stable unintended steady state. This situation might arise if policymakers are unwilling to pursue an aggressive increase in government spending, e.g. because of concerns about the size of government debt, unless deflation is unmistakable and significant. This is one possible explanation for Japan's experience.

An alternative avenue, which may perhaps be appealing for the recent US experience, is that the initial negative expectational shock may have placed us very close to the saddlepath. We would then move toward the low-inflation steady state, where the economy could hover for an extended period of time, before "declaring" itself, i.e. beginning a long path back to the targeted steady state at $\pi^{*}$ or falling into a deflationary spiral. An extension of this line of thought is that after the initial expectational shock the economy may have been in the deflation trap region, and that the fiscal stimulus measures then pushed the economy close to the saddle path, with a weak recovery.

For the US in the 1930s, one might argue, along the lines of Eggertsson (2008), that the New Deal policies to stabilize prices had both direct and expectational effects that prevented deflation and assisted in initiating a fragile recovery, which finally became robust when a large fiscal stimulus, taking the form of war-time expenditures, pushed the economy back to full employment.

However, we now set aside these possible explanations and pursue an alternative (and in a sense complementary) approach that modifies the model to incorporate an asymmetry in the adjustment of wages and prices. To do this we modify the quadratic functional form $k\left(\pi_{t, j}\right)=0.5\left(\pi_{t, j}-1\right)^{2}$ for price adjustment costs, which was made only because it is standard and analytically convenient. There is a long tradition of arguing that agents are subject to money illusion, which is manifested mainly in a strong resistance to reductions in nominal wages. ${ }^{9}$ To incorporate this one can introduce an asymmetry in $k\left(\pi_{t, j}\right)$, with agents being more averse to reductions in $\pi_{t, j}$ than to equal increases in $\pi_{t, j}$. For convenience we adopt an extreme form of

\footnotetext{
${ }^{9}$ For a recent argument that people strongly resist reductions in wages, see Akerlof and Shiller (2009), Ch. 9.
} 
this asymmetry,

$$
k\left(\pi_{t, j}\right)=\left\{\begin{array}{c}
0.5\left(\pi_{t, j}-1\right)^{2} \text { for } \pi_{t, j} \geq \underline{\pi} \\
+\infty \text { for } \pi_{t, j}<\underline{\pi}
\end{array} .\right.
$$

This, in effect, places a lower bound of $\underline{\pi}$ on $\pi_{t, j}$. The result is that $\pi_{t}=$ $H_{\pi}\left(\pi_{t+1}^{e}, c_{t+1}^{e}, g_{t}\right)$, equation (1), is replaced by

$$
\pi_{t}=\left\{\begin{array}{c}
H_{\pi}\left(\pi_{t+1}^{e}, c_{t}, g_{t}\right) \text { if } H_{\pi}\left(\pi_{t+1}^{e}, c_{t}, g_{t}\right) \geq \underline{\pi} \\
\underline{\pi}, \text { otherwise }
\end{array}\right.
$$

The qualitative features of the phase diagram depend critically on the value of $\underline{\pi}$, and I focus on one possible value that leads to particularly interesting results, namely

$$
\underline{\pi}=\beta \text {. }
$$

Quantitatively, this choice is perhaps not implausible. If in most sectors there is great resistance to deflation, but decreases in prices cannot be prevented in some markets, then an inflation floor at a low rate of deflation might arise. ${ }^{10}$ The assumption $\underline{\pi}=\beta$ is obviously special, ${ }^{11}$ but the results for this case will informative also for values $\underline{\pi} \approx \beta$.

The resulting phase diagram, shown in Figure 2, is very revealing. It can be seen that the deflation trap region of divergent paths has been replaced by a region that converges to a continuum of stationary states at $\pi_{t}=\pi^{e}=\underline{\pi}$ and $c_{t}=c^{e}=c$ for $0 \leq c \leq c_{L}$, where $c_{L}$ is the level of $c$ such that $H_{\pi}\left(\beta, c_{L}, g\right)=\underline{\pi}$. The pessimistic expectations shock that in Figure A1 leads to a divergent trajectory culminating in continually falling inflation and consumption, now converges to $\pi=\underline{\pi}=\beta$, i.e. a deflation rate equal to the negative of the discount rate, and a low level of consumption and output. This set of stationary states constitutes the stagnation regime of the model. This is a very Keynesian regime, in that it is one in which output is constrained by the aggregate demand for goods. In contrast to the rational expectations analysis of Benhabib, Schmitt-Grohe, and Uribe (2001a), in which the unintended low deflation steady state has levels of output and consumption that are not much different from their levels in the intended steady state, in the stagnation regime consumption and welfare can be much lower than at the $\pi^{*}$ steady state.

\footnotetext{
${ }^{10}$ Depending on assumptions about the CRRA parameter, a low rate of deflation might also arise as a result of zero wage inflation combined with technical progress.

${ }^{11}$ And one at which a bifurcation of the system occurs.
} 


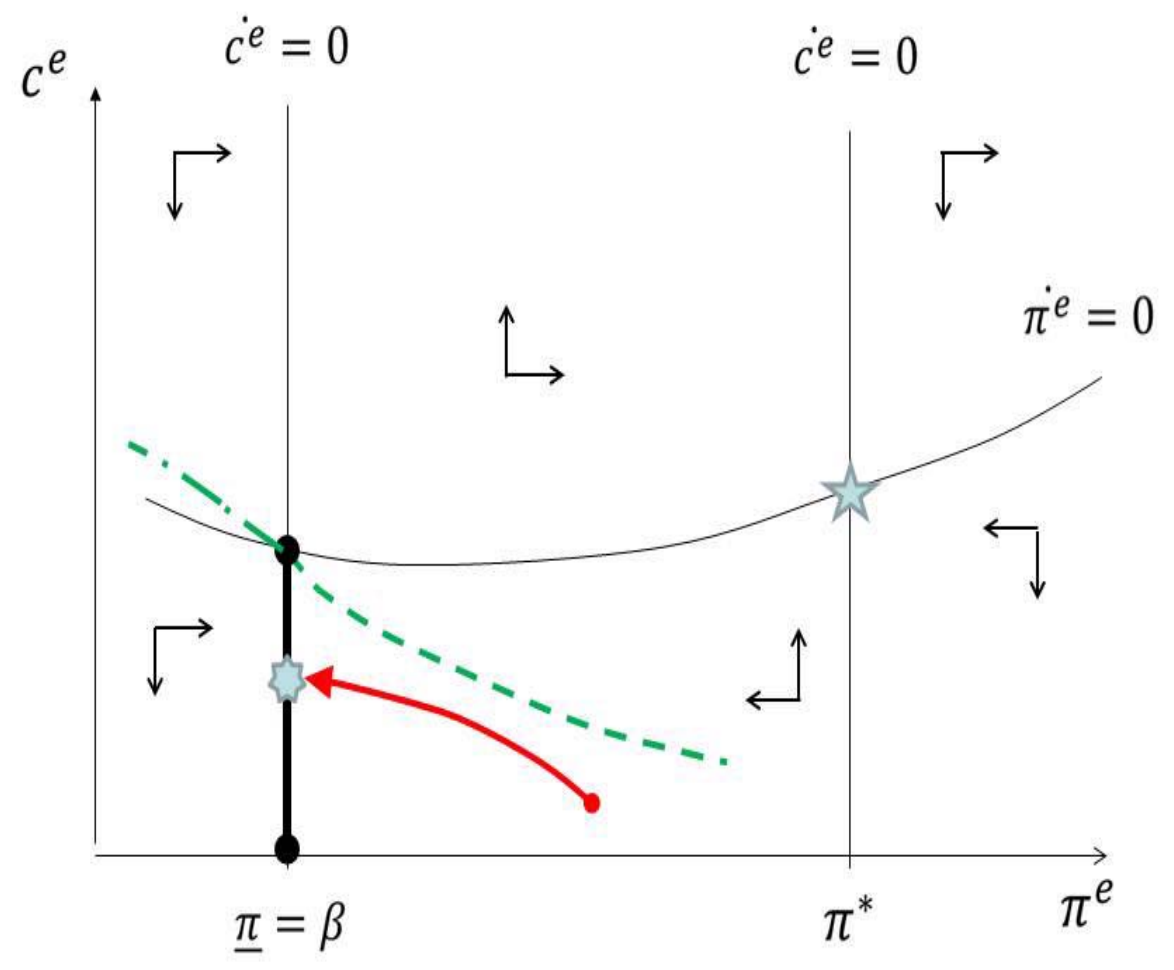

Figure 2: The stagnation regime.

The stagnation regime has interesting comparative statics. A small increase in government spending $g$ raises output by an equal amount, i.e. the government spending multiplier is one. Government spending does not stimulate increases in consumption, but it also does not crowd out consumption. Evans and Honkapohja (2010) noted this result in the temporary equilibrium, for given expectations, and in the stagnation regime the result holds for the continuum of stagnation regime stationary states. In this regime, an increase in $g$ increases output $y$ but has no effect on either $c_{t}$ or $\pi_{t}$, provided $H_{\pi}(\underline{\pi}, c, g)<\underline{\pi}$. 
The stagnation regime also has interesting dynamics that result from sufficiently large increases in $g$. Using Lemma 1 of Evans, Guse, and Honkapohja (2008) it follows that there is a critical value $\hat{g}$ such that for $g>\hat{g}$ we have $H_{\pi}(\underline{\pi}, c, g)>\underline{\pi}$. If $g$ is increased to and held at a value $g>\hat{g}$ then at this point $\pi_{t}>\underline{\pi}$, leading to increasing $\pi^{e}$, higher $c$ and higher $c^{e} \cdot{ }^{12}$ This process is self-reinforcing, and once $\left(\pi^{e}, c^{e}\right)$ crosses the saddlepath boundary it also becomes self-sustaining. That is, at this point the natural stabilizing forces of the economy take over. Government spending can then be reduced back to normal levels, and the economy will follow a path back to $\left(\pi^{*}, c^{*}\right)$, the intended steady state. ${ }^{13}$ One way to interpret these results is that the temporary increase in $g$ provides enough lift to output and inflation that the economy achieves "escape velocity" from the stagnation regime. ${ }^{14}$ Under a standard "Leeper-type" rule for setting taxes, the temporary increase in $g_{t}$ leads to a build-up of debt during the period of increased government spending, and is then followed by a period in which debt gradually returns to the original steady state value, due to the reduction in $g_{t}$ to normal levels and a period of higher taxes. For an illustrative simulation of all the key variables, including debt, see Evans, Guse, and Honkapohja (2008).

It is important to note that the impact of temporary increases in government spending does not depend on a failure of Ricardian equivalence. In the model of Evans, Guse, and Honkapohja (2008) and the modified model here, the impact of government spending is the same whether it is financed by taxes or by debt. This is also true in the infinite-horizon version of Evans and Honkapohja (2010) in which we explicitly impose Ricardian Equivalence on private-agent decision-making. Thus, within our models, the fiscal policy tool is temporary increases in government spending, not reductions in taxes or increases in transfers. However, it is possible, of course, that for a variety of reasons Ricardian Equivalence may fail, e.g. because of the presence of liquidity-constrained households, in which case tax cuts financed by bond

\footnotetext{
${ }^{12}$ The $\dot{\pi}^{e}=0$ curve is obtained by setting $\pi=\pi_{t}=\pi_{t}^{e}$ in equation (1). An increase in $g$ can be seen as shifting the $\dot{\pi}^{e}=0$ curve down. Once it shifts below the stationary value of $c$ in the stagnation regime, $\pi_{t}$ and $\pi_{t}^{e}$ will start to rise.

${ }^{13}$ In contrast to traditional Keynesian "multipliers," the temporary increase in government spending here results in a dynamic path leading to a permanently higher level of output.

${ }^{14}$ In the April 3, 2010 edition of the Financial Times, Lawrence Summers, the Director of the US National economic Council, was quoted as saying that the economy "appears to be moving towards escape velocity."
} 
sales can be effective. ${ }^{15}$ Similarly if Ricardian Equivalence fails because longhorizon households do not internalize the government's intertemporal budget constraints, then tax reductions can again be effective. However, the most reliable fiscal tool is temporary increases in government spending.

What if the condition $\underline{\pi}=\beta$ does not exactly hold? If $\underline{\pi} \neq \beta$ but $\underline{\pi} \approx \beta$ then the results can be qualitatively similar for long stretches of time. For example if $\underline{\pi} \approx \beta$ and $\underline{\pi}>\beta$ then the targeted steady state will be globally stable, but the corresponding path followed by the economy once inflation has fallen to $\underline{\pi}$ will include slow increases in $c$ and $c^{e}$ before eventually inflation increases and the economy returns to the targeted steady state. ${ }^{16}$ An interesting feature of the modified model is that, under learning, the inflation floor is not itself a barrier to reaching the targeted steady state. Indeed, it acts to stabilize the economy in the sense that, in the presence of large negative expectation shocks, it prevents the economy from falling into a deflationary spiral and a divergent path. However, although the economy reaches a stable region in the stagnation regime, output is persistently depressed below the steady state that policymakers are aiming to reach.

\section{Policy}

We now discuss at greater length the policy implications when the economy is at risk of becoming trapped in the stagnation regime. Although the discussion is rooted in the model presented, it also will bring in some factors that go beyond our simple model. We have used a closed-economy model without capital, a separate labor market, or an explicit role for financial intermediation and risk. These dimensions provide scope for additional policy levers. ${ }^{17}$

\footnotetext{
${ }^{15}$ The $\$ 858$ billion measure, passed by Congress and signed into law in December 2010 , includes tax cuts and extended unemployment benefits that will likely have a significant positive effect on aggregate demand and output in 2011 due in part to relaxed liquidity constraints for lower-income households.

${ }^{16}$ If instead $\underline{\pi} \approx \beta$ and $\underline{\pi}<\beta$ then the stagnation regime at $\underline{\pi}$ will be accomanpanied by a slow decline in consumption and output. Such a decline would also result if $\underline{\pi}=\beta$, with the economy in the stagnation regime, and the policymakers increase the interest rate above the ZLB $R=1$.

${ }^{17}$ The discussion here is not meant to be exhaustive. Three glaring omissions, from the list of policies considered here, are: dealing with the foreclosure problem in the US, ensuring that adequate lending is available for small businesses, and moving ahead with
} 


\subsection{Fiscal policy}

The basic policy implications of the model are quite clear, and consistent with Evans, Guse, and Honkapohja (2008) and Evans and Honkapohja (2010). If the economy is hit by factors that deliver a shock to expectations that is not too large, then the standard monetary policy response will be satisfactory in the sense that it will ensure the return of the economy to the intended steady state. However, if there is a large negative shock then standard policy will be subject to the zero-interest rate lower bound, and for sufficiently large shocks even zero interest rates may be insufficient to return the economy to the targeted steady state. In the modified model of the present paper, the economy may converge instead to the stagnation regime, in which there is deflation at a rate equal to the net discount rate and output is depressed. In this regime consumption is at a low level in line with expectations, which in turn will have adapted to the households' recent experience.

If the economy is trapped in this regime, sufficiently aggressive fiscal policy, taking the form of temporary increases in government spending, will dislodge the economy from the stagnation regime. A relatively small increase will raise output and employment but will not be sufficient to push the economy out of the stagnation regime. However, a large enough temporary increase in government spending will push the economy into the stable region and back to the targeted steady state. This policy would also be indicated if the economy is en route to the stagnation regime, and may be merited even if the economy is within the stable region, but close enough to the unstable region that it would result in a protracted period of depressed economic activity.

Because of Ricardian equivalence, tax cuts are ineffective unless they are directed towards liquidity constrained households. However, in models with capital a potentially effective policy is investment tax credits. If the investment tax credits are time limited then they work not only by reducing the cost of capital to firms, but also by rescheduling investment from the future to now or the near future, when it is most needed. Investment tax credits could also be made state contingent, in the sense that the tax credit would disappear after explicit macroeconomic goals, e.g. in terms of GDP growth, are reached.

In the US an effective fiscal stimulus that operates swiftly is federal aid to state and local governments. This was provided on a substantial scale

the implementation of regulatory reform in the financial sector. 
through the ARRA in 2009 and 2010, but this money will largely disappear in 2011. Why are states in such difficulties? The central reason is that they fail to smooth their revenues (and expenditures) over the business cycle. States require themselves to balance the budget, and tend to do this year by year (or in some States biennium by biennium). Thus, when there is a recession, state tax revenues decline and they are compelled to reduce expenditures. This is the opposite of what we want: instead of acting as an automatic stabilizer, which is what happens at the federal level, budget balancing by states in recessions acts to intensify the recession. Indeed, in the US the ARRA fiscal stimulus has largely been offset by reductions in government spending at the sate and local level.

\subsection{Fiscal policy and rainy day funds}

This does not have to be. States should follow the recommendation that macroeconomists have traditionally given to national economies, which is to balance the budget over the business cycle. This can be done by the states setting up rainy day funds, building up reserves in booms to use in recessions. ${ }^{18}$ A common objection to this proposal is that if a state builds up a rainy day fund, then politicians will spend it before the next recession hits. This objection can be dealt with. Setting up the rainy day fund should include a provision that drawing on the fund is prohibited unless specified economic indicators are triggered. The triggers could be based on either national or state data (or a combination). For example, a suitable national indicator would be two successive quarterly declines of real GDP. State level triggers could be based on the BLS measures of the unemployment rate, e.g. an increase of at least two percentage points in the unemployment rate over the lowest rate most recently achieved. Once triggered the fund would be available for drawing down over a specified period, e.g. three years or until the indicators improve by specified amounts. After that point, the rainy day fund would have to be built up again, until an appropriate level is reached. Obviously there are many provisions that would need to be thought through carefully and specified in detail. However, the basic point seems unassailable that this approach provides a rational basis for managing state and local

\footnotetext{
${ }^{18}$ Of course the size of the fund needs to be adequate. The state of Oregon recently started up a rainy day fund, which has turned out to be very useful following the recent recession, but the scale was clearly too small.
} 
financing, and that the political objections can be overcome by specifying the rules in advance.

It is also worth emphasizing that the establishment of rainy day funds would act to discipline state spending during expansions. Instead of treating the extra tax revenue generated during booms as free resources, to be used for additional government spending or for distribution to taxpayers, the revenue would go into a fund set aside for use during recessions. This is simply prudent management of state financial resources, which leads to a more efficient response to aggregate fluctuations. ${ }^{19}$

As of late 2010, there appeared clearly to be a need for fiscal stimulus taking the form of additional federal aid to states. Politically this is difficult because people are distrustful of politicians and are concerned about deficits and debt. A natural proposal therefore is to provide additional federal money to states during 2011, contingent on the states agreeing to set up adequate rainy day funds, to which contributions would begin as soon as there is a robust recovery. This proposal has the attraction that it provides states with funds that are needed in the short-term to avoid impending layoffs of state and local government employees, but in return for changing their institutions in such a way that federal help will be much less likely to be needed during future recessions.

\subsection{Quantitative easing and the composition of the Fed balance sheet}

Since aggressive fiscal policy in the near term may be politically unpromising, especially in the US, one must also consider whether more can be done with monetary policy.

In the version of the model used here, agents use short-horizon decision rules, based on Euler equations, and once the monetary authorities have reduced (short) interest rates to zero, there is no scope for further policy easing. In Evans and Honkapohja (2010) we showed that the central qualitative

\footnotetext{
${ }^{19}$ Similar issues arise in the European context. Eurozone countries are committed to the Stability and Growth Pact, which in principle limits deficit and debt levels of member countries. However, these limits have been stressed by recent events and enforcement appears difficult or undesirable in some cases. Reform may therefore be needed. An appropriate way forward would be to require every member country to set up a rainy day fund, during the next expansion, to which contributions are made until a suitable fund level is reached.
} 
features of the model carry over to infinite-horizon decision rules, and the same would be true of the modified framework here. In this setting there is an additional monetary policy tool, namely policy announcements directed toward influencing expectations of future interest rates. By committing to keep short-term interest rates low for an extended period of time, the Fed can aim to stimulate consumption. An equivalent policy, which in practice is complementary, would be to move out in the maturity structure and purchase longer dated bonds. As Evans and Honkapohja (2010) demonstrates, however, such a policy may still be inadequate: even promising to keep interest rates low forever may be insufficient in the presence of a very large negative expectational shock.

Since financial intermediation and risk have been central to the recent financial crisis, and continue to play a key role in the current economy, there are additional central bank policy interventions that would be natural. One set of policies is being considered by the Federal Reserve Bank under the name of "quantitative easing" or QE2. ${ }^{20}$ Open market purchases of assets at longer maturities can reduce interest rates across the term-structure, providing further channels for stimulating demand. More generally the Fed could alter its balance sheet to include bonds with some degree of risk. If expansionary fiscal policy is considered infeasible politically, then quantitative easing or changing the composition of the Federal Reserve balance sheet becomes an attractive option.

In an open economy model, there are additional channels for quantitative easing. If the US greatly expands its money stock, and other countries do not do so, or do so to a lesser extent, then foreign exchange markets are likely to conclude that there is likely, in the medium or long run, to be a greater increase in prices in the US than the rest or the world, and therefore a relative depreciation of the dollar. Unlike wages and goods prices, which respond sluggishly to changes in the money supply, foreign exchange markets often react very quickly to policy changes, and thus quantitative easing could lead to a substantial depreciation of the dollar now. ${ }^{21}$ In a more aggressive version of this policy the Fed would directly purchase foreign bonds. This would tend to boost net exports and output and help to stimulate growth in the US. This policy could, of course, be offset by monetary expansions in other countries, but some countries may be reluctant to do so. ${ }^{22}$

\footnotetext{
${ }^{20}$ As noted in the postscript, QE2 was introduced in November 2010.

${ }^{21}$ This is the mechanism of the Dornbusch (1976) model.

${ }^{22}$ And if all countries engaged in monetary expansion, this might increase inflation
} 
Another set of policies being discussed involve new or more explicit commitments by policymakers to achieve specified inflation and price level targets. For example, one proposal would commit to returning to a price level path obtained by extrapolating using a target inflation rate of, say, $2 \%$ p.a., from an earlier base, followed by a return to inflation targeting after that level is achieved. From the viewpoint of adaptive learning, a basic problem with all of these approaches is that to the extent that expectations are grounded in data, raising $\pi^{e}$ may require actual observations of higher inflation rates. As briefly noted above, policy commitments and announcements may indeed have some impact on expectations, but the evolution of data will be decisive.

An additional problem, however, is that there are some distributional consequences that are not benign. Households that are savers, with a portfolio consisting primarily in safe assets like short maturity government bonds, have already been adversely affected by a monetary policy in which the nominal returns on these assets has been pushed down to near zero. A policy commitment at this juncture, which pairs an extended period of continued near zero interest rates with a commitment to use quantitative easing aggressively in order to increase inflation, has a downside of adversely affecting the wealth position of households who are savers aiming for a low risk portfolio.

\subsection{A proposal for a mixed fiscal-monetary stimulus}

If political constraints are an impediment to temporary increases in government spending at the Federal level in the US, as they currently appear to be in the United States, it may still be possible to use a fiscal-monetary policy mix that is effective. State and local government's are constrained in the United States to balance their budgets, but there is an exception in most states for capital projects. At the same time there is a clear-cut need throughout the United States to increase investment in infrastructure projects, as the US Society of Civil Engineers has been stressing for some time. In January 2009 the Society gave a grade of D to the nation's infrastructure. Large investments will be required in the nation's bridges, wastewater and sewage treatment, roads, rail, dams, levees, air traffic control and school buildings. The need for this spending is not particularly controversial. The Society estimates $\$ 2.2$ trillion over five years as the total amount needed (at all levels

expectations. 
of government) to put this infrastructure into a satisfactory state. ${ }^{23}$ Thus there is no shortage of useful investment that can be initiated.

The scale of the infrastructure projects needed is appropriate, since a plausible estimate of the cumulative short-fall of GDP relative to potential GDP, as of January 2011 , is in excess of $\$ 1$ trillion. $^{2425}$ The timing and inherent lags in such projects may be acceptable. If we are in the stagnation regime, or heading toward or near the stagnation regime, then it is likely to be some time before we return to the targeted steady state. Projects that take several years may then be quite attractive. The historical evidence of ? indicate that in the aftermath of recessions associated with banking crises, the recovery is particularly slow.

Furthermore, this area of expenditure appears to be an ideal category for leading a robust recovery. In the stagnation regime, the central problem is deficient aggregate demand. In past US past recessions, household consumption and housing construction have often been the sectors that lead the economic recovery. But given the excesses of the housing boom and the high indebtedness of households, do we want to rely on, or encourage, a rapid growth of consumption and residential construction in the near future? It would appear much more sensible to stimulate spending in the near term on infrastructure projects that are clearly beneficial, and that do not require us to encourage households to reduce their saving rate. Furthermore, once a robust recovery is underway, these capital investments will raise potential output and growth because of their positive supply-side impact on the nation's capital stock.

How would this be financed? State and local governments can be expected to be well-informed about a wide range of needed infrastructure projects, but financing the projects requires issuing state or municipal bonds. Many states and localities are currently hard pressed to balance their budget, and this may make it difficult for them to issue bonds to finance the projects

\footnotetext{
${ }^{23}$ For example, see the January 28,2009 , New York Times story "US Infrastructure Is In Dire Straits, Report Says."

${ }^{24}$ Assuming a $6 \%$ natural rate of unemployment and an Okun's law parameter of between 2 and 2.5 gives a range of $\$ 1.2$ trillion to $\$ 1.5$ trillion for the GDP shortfall if the unemployment rate, over 2011, 2012 and 2013, averages $8.5 \%, 7.5 \%$ and $6.5 \%$, respectively.

${ }^{25}$ For comparison the ARRA stimulus program was estimated by the Congessional Budget Office to have reduced the unemployment rate, relative to what it would otherwise have been, by between 0.7 and 1.8 percentage points. A number of commentators argued in early 2009 that the scale of the ARRA might be inadequate.
} 
at interest rates that are attractive. Here both the Federal Reserve and the Treasury can play key roles. The Treasury could announce that, up to some stated amount, they would be willing to purchase state and local bonds for qualifying infrastructure projects. The Treasury would provide financing, at relatively low interest rates, for productive investment projects that are widely agreed to be urgently needed. Ideally there would be a Federal subsidy to partially match the state or local government expenditure on infrastructure investment, as has often been true in the past. This would both make the investment more attractive and help to orchestrate a coordinated program over the near term.

The ARRA did include a substantial provision for funding infrastructure through "Build America Bonds," which has provided a subsidy by the Treasury to state and local governments issuing bonds for infrastructure projects. (Interest on these bonds is not tax-exempt, so the subsidy is partially offset by greater federal taxes received on interest). The Build America Bonds have been very popular, but there is clearly room for a much larger infrastructure spending at the state and local level.

The Treasury could be involved in vetting and rationing the proposed projects, ensuring geographic diversity as well as quality and feasibility. One possibility would be for the President to announce a plan that encourages states and localities to submit proposals for infrastructure projects, which are then assessed. To finance their purchases of state and municipal bonds, the Treasury would issue bonds with a maturity in line with those acquired. For the Treasury there would be no obvious on-budget implications, since the extra Treasury debt issued by the Treasury to finance purchases of the state and municipal bonds would be offset by holdings of those bonds.

What would be the role of the Federal Reserve? The increase in infrastructure projects would go hand-in-glove with a policy of quantitative easing in which the Fed buys longer-dated US Treasuries, extending low interest rates further out the yield curve. In effect, the Fed would provide financing to the Treasury, and the Treasury would provide financing to states and local government, at rates that make investment in infrastructure projects particularly attractive now and in the near future. In principle, the Federal Reserve could also directly purchase the state and municipal bonds. Alternatively they could provide financing indirectly by making purchases in the secondary market for municipal bonds.

Thus this proposal meshes well with the current discussion within the Federal Reserve Bank for quantitative easing, with the additional feature 
that the injections of money in exchange for longer-dated Treasuries would be in part aimed at providing financing for new spending on infrastructure investment projects.

The three proposals discussed above are complementary. Federal aid to states and localities is needed in the near term to reduce current state budget problems and avoid layoffs. A commitment by states to set up rainy day funds during the next expansion will help ensure that state budgeting is put on a secure footing going forward. A large infrastructure program can provide a major source of demand that will also expand the nation's capital stock and enhance future productivity. Finally, quantitative easing by the Federal Reserve can help provide an environment in which the terms for financing infrastructure projects is attractive.

\section{Conclusions}

In the model of this paper, if an adverse shock to the economy leads to a large downward shift in consumption and inflation expectations, the resulting path can converge to a stagnation regime, in which output and consumption remain at low levels, accompanied by steady deflation. Small increases in government spending will increase output, but may leave the economy within the stagnation regime. However, a sufficiently large temporary increase in government spending can dislodge the economy from the stagnation regime and restore the natural stabilizing forces of the economy, eventually returning the economy to the targeted steady state.

The aggressive monetary policy response of the Federal Reserve Bank over 2007-9, together with the TARP intervention and the limited ARRA fiscal stimulus, may well have been helped to avert a second Depression in the US. However, as of late 2010, US data showed continued high levels of unemployment, modest rates of GDP growth, and very low and possibly declining inflation. Although the economy has stabilized, there remains the possibility of either convergence to the stagnation regime or of an unusually protracted period before a robust recovery begins.

Although forecasting GDP growth is notoriously difficult, it seems almost certain that in the near-term the economy will continue to have substantial excess capacity and elevated unemployment. In this setting there is a case 
for further expansionary policies. ${ }^{26}$ My suggestions include a combination of additional federal aid to state and local governments, in return for a commitment by states to set up rainy day funds during the next expansion, quantitative easing by the Federal Reserve, and a large-scale infrastructure program, funded indirectly by the US Treasury and accommodated by the Federal Reserve as part of the program of quantitative easing.

\section{Postscript}

Between the end of October 2010, when this paper was initially written, and the beginning of April 2011, there were significant changes in the United States in both macroeconomic policy and the trajectory of the economy. The US Federal Reserve Open Market Committee announced in November 2010 a new round of quantitative easing (referred to as QE2, i.e. quantitative easing, round two), which is expected to total $\$ 600$ billion for purchases of longer-dated Treasury bonds over an eight-month period ending in June 2011. In addition, in December 2010 the US Congress passed, and the President signed into law, a new fiscal stimulus measure that included, among other things, temporary reductions in payroll taxes and extended unemployment benefits, as well as continuation of tax reductions introduced in 2001 that would otherwise have expired. Thus, while the specific policies recommended in this paper were not all adopted, there was shift toward a more expansionary stance in both monetary and fiscal policy.

Over November 2010 - March 2011 the US macroeconomic data have also been somewhat more encouraging. The unemployment rate, which had been stuck in the range $9.5 \%-9.8 \%$ range, declined over three months to $8.8 \%$ in March 2011, while the 12-month CPI inflation rate, excluding food and energy, which had been in decline and was at $0.6 \%$ in October 2010, increased to $1.1 \%$ in February 2011. While the unemployment rate is considerably above its pre-crisis levels and the inflation rate remains below the (informal) target of $2 \%$, this data, combined with the recent monetary and fiscal policy stimulus, provide some grounds for hope that we will follow a path back toward the intended steady state and avoid convergence to the stagnation regime. As has been emphasized in the main text, however, following a large expectational shock, in addition to paths converging to the stagnation regime,

\footnotetext{
${ }^{26}$ Additional monetary easing was introduced in November 2010 and expansionary fiscal measures were passed in December 2010.
} 
there are also paths that converge very slowly to the desired steady state. Under current forecasts of the unemployment rate a case can still be made for additional infrastructure spending over the next new years, especially given the uncertainty attached to macroeconomic forecasts: there remains downside risk as well as upside hope.

The case for a restructuring of US state finances, and of national finances within the Euro area, continues to appear compelling. In the US, states and localities are under pressure to reduce expenditures in the near-term because of the reduced tax revenues, which are the lagged result of the recession, and in several European countries there is still the potential for sovereign debt crises, Establishing rainy-day funds during the next expansion, once the recovery is clearly established, would provide the needed fiscal reassurance and flexibility for rational countercyclical fiscal policy, if needed during a future major downturn. A commitment now to establish a rainy-day funds in the future, should be part of every medium-term financial plan. 


\section{Appendix}

The framework for the model is from Evans, Guse, and Honkapohja (2008), except that random shocks are omitted and the interest-rate rule is modified as discussed in the main text. There is a continuum of householdfirms, which produce a differentiated consumption good under monopolistic competition and price-adjustment costs. There is also a government which uses both monetary and fiscal policy and can issue public debt as described below. Agent j's problem is

$$
\begin{gathered}
\operatorname{Max} E_{0} \sum_{t=0}^{\infty} \beta^{t} U_{t, j}\left(c_{t, j}, \frac{M_{t-1, j}}{P_{t}}, h_{t, j}, \pi_{t, j}\right) \\
\text { st. } c_{t, j}+m_{t, j}+b_{t, j}+\Upsilon_{t, j}=m_{t-1, j} \pi_{t}^{-1}+R_{t-1} \pi_{t}^{-1} b_{t-1, j}+\frac{P_{t, j}}{P_{t}} y_{t, j},
\end{gathered}
$$

where $c_{t, j}$ is the Dixit-Stiglitz consumption aggregator, $M_{t, j}$ and $m_{t, j}$ denote nominal and real money balances, $h_{t, j}$ is the labor input into production, $b_{t, j}$ denotes the real quantity of risk-free one-period nominal bonds held by the agent at the end of period $t, \Upsilon_{t, j}$ is the lump-sum tax collected by the government, $P_{t, j}$ is the price of consumption $\operatorname{good} j, \pi_{t, j}=\frac{P_{t, j}}{P_{t-1, j}}, y_{t, j}$ is output of good $j, P_{t}$ is the aggregate price level and the inflation rate is $\pi_{t}=P_{t} / P_{t-1}$. The utility function has the parametric form

$$
U_{t, j}=\frac{c_{t, j}^{1-\sigma_{1}}}{1-\sigma_{1}}+\frac{\chi}{1-\sigma_{2}}\left(\frac{M_{t-1, j}}{P_{t}}\right)^{1-\sigma_{2}}-\frac{h_{t, j}^{1+\varepsilon}}{1+\varepsilon}-\gamma k\left(\pi_{t, j}\right),
$$

where $\sigma_{1}, \sigma_{2}, \varepsilon, \gamma>0$. The final term parameterizes the cost of adjusting prices in the spirit of Rotemberg (1982), specifically taking the quadratic form

$$
k\left(\pi_{t, j}\right)=\frac{1}{2}\left(\pi_{t, j}-1\right)^{2} .
$$

Production function for good $j$ is given by $y_{t, j}=h_{t, j}^{\alpha}$, where $0<\alpha<1$. Output is differentiated and firms operate under monopolistic competition. Each firm faces a downward-sloping demand curve given by $P_{t, j}=\left(y_{t, j} / Y_{t}\right)^{-1 / \nu} P_{t}$. Here $P_{t, j}$ is the profit maximizing price set by firm $j$ consistent with its production $y_{t, j}$, and $\nu>1$ is the elasticity of substitution between two goods. $Y_{t}$ is aggregate output, which is exogenous to the firm.

Using the household-firm's first-order Euler conditions for optimal choices of prices $P_{t, j}$ and consumption $c_{t, j}$, and using the representative agent as- 
sumption, we get the equations for the temporary equilibrium at time $t$ :

$$
\begin{aligned}
\left(\pi_{t}-1\right) \pi_{t}= & \beta\left(\pi_{t+1}^{e}-1\right) \pi_{t+1}^{e}+\frac{\nu}{\alpha \gamma}\left(c_{t}+g_{t}\right)^{(1+\varepsilon) / \alpha} \\
& -\gamma^{-1}(\nu-1)\left(c_{t}+g_{t}\right) c_{t}^{-\sigma_{1}}
\end{aligned}
$$

and

$$
c_{t}=c_{t+1}^{e}\left(\pi_{t+1}^{e} / \beta R_{t}\right)^{\sigma_{1}}
$$

where we assume $\pi_{t}>0.5$.

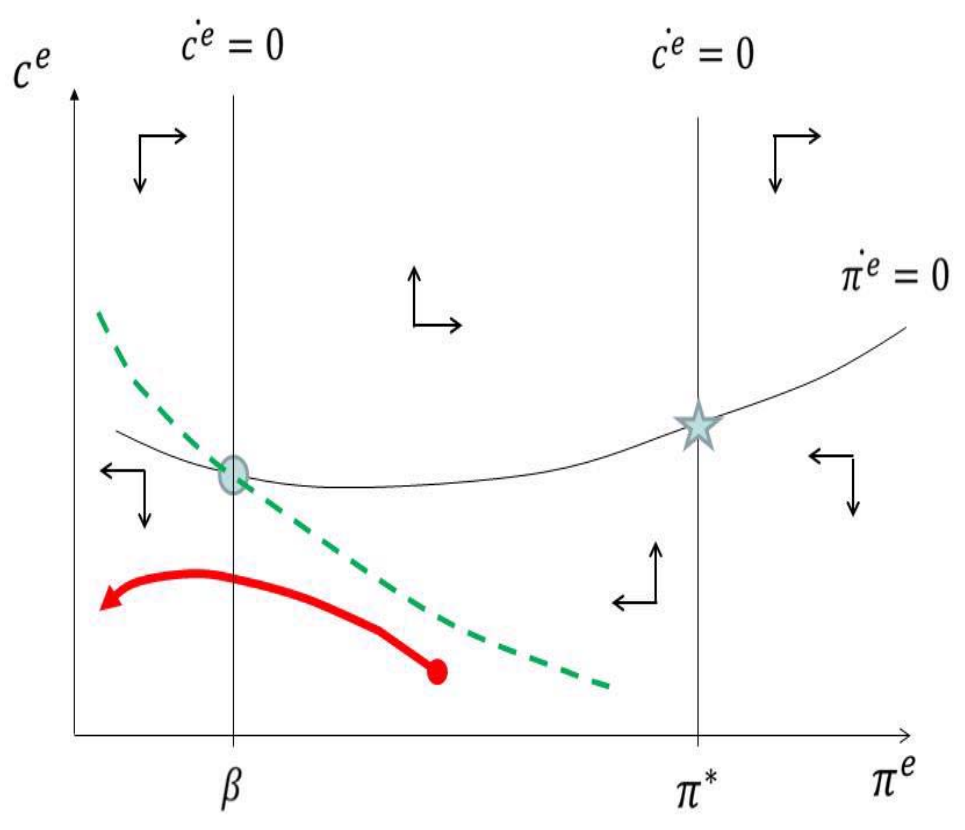

Figure A1: Divergent paths can result from large negative expectation shocks.

The government's flow budget constraint is $b_{t}+m_{t}+\Upsilon_{t}=g_{t}+m_{t-1} \pi_{t}^{-1}+$ $R_{t-1} \pi_{t}^{-1} b_{t-1}$, where $b_{t}$ is the real quantity of government debt, and $\Upsilon_{t}$ is the real lump-sum tax collected. The rule for lump-sum taxes is $\Upsilon_{t}=\kappa_{0}+\kappa b_{t-1}$, where $\beta^{-1}-1<\kappa<1$ so that fiscal policy is "passive" in the terminology 
of Leeper (1991). The interest-rate rule, $R_{t}=f\left(\pi_{t+1}^{e}\right)$, is assumed to be a linear spline

$$
f\left(\pi^{e}\right)=\min \left\{1,\left(\pi^{*} / \beta\right)+\theta\left(\pi^{e}-\pi^{*}\right)\right\}
$$

where $\theta>\beta^{-1}$.

Under adaptive learning, for the case without an inflation floor, the phase diagram, giving the dynamics in the small gain case, is shown in the accompanying Figure. Incorporating an inflation floor at $\underline{\pi}=\beta$, as in Section 3, leads to the stagnation regime case shown in Figure 2 and emphasized in the main text of the current paper.

\section{References}

Akerlof, G. A., And R. J. Shiller (2009): Animal Spirits. Princeton University Press, Princeton, NJ.

Benhabib, J., S. Schmitt-Grohe, and M. Uribe (2001a): "Monetary Policy and Multiple Equilibria," American Economic Review, 91, 167-186.

(2001b): "The Perils of Taylor Rules," Journal of Economic Theory, 96, 40-69.

Bullard, J. (2010): "Seven Faces of The Peril," Federal Reserve Bank of St. Louis Review, 92, 339-352.

Cobham, D., Ø. Eitrheim, S. Gerlach, and J. F. Qvigstad (eds.) (2010): Twenty Years of Inflation Targeting: Lessons Learned and Future Prospects. Cambridge University Press, Cambridge.

Dornbusch, R. (1976): "Expectations and Exchange Rate Dynamics," Journal of Political Economy, 84, 1161-1176.

Eggertsson, G. B. (2008): "Was the New Deal Contractionary?," Working paper.

Eggertsson, G. B., And M. Woodford (2003): "The Zero Bound on Interest Rates and Optimal Monetary Policy," Brookings Papers on Economic Activity, (1), 139-233. 
Evans, G. W. (1985): "Bottlenecks and the Phillips Curve: A Disaggregated Keynesian Model of Inflation, Output and Unemployment," Economic Journal, 95, 345-357.

Evans, G. W., E. Guse, and S. Honkapohja (2008): "Liquidity Traps, Learning and Stagnation," European Economic Review, 52, 1438-1463.

Evans, G. W., and S. Honkapohja (2001): Learning and Expectations in Macroeconomics. Princeton University Press, Princeton, New Jersey. (2010): "Expectations, Deflation Traps and Macroeconomic Policy," in Cobham, Eitrheim, Gerlach, and Qvigstad (2010), chap. 12, pp. 232260 .

Evans, G. W., S. Honkapohja, and K. Mitra (2009): "Anticipated Fiscal Policy and Learning," Journal of Monetary Economics, 56, 930953.

Krugman, P. R. (1998): "It's Baaack: Japan's Slump and the Return of the Liquidity Trap," Brookings Papers on Economic Activity, (2), 137-205.

Leeper, E. M. (1991): 'Equilibria under 'Active' and 'Passive' Monetary and Fiscal Policies," Journal of Monetary Economics, 27, 129-147.

Preston, B. (2006): "Adaptive Learning, Forecast-based Instrument Rules and Monetary Policy," Journal of Monetary Economics, 53, 507-535.

Reifschneider, D., and J. C. Williams (2000): "Three Lessons for Monetary Policy in a Low-Inflation Era," Journal of Money, Credit and Banking, 32, 936-966.

Rotemberg, J. J. (1982): "Sticky Prices in the United States," Journal of Political Economy, 90, 1187-1211. 